Joyce LIDDLE

\title{
LEADING CITIZEN-DRIVEN GOVERNANCE: COLLECTIVE REGIONAL AND SUB-REGIONAL LEADERSHIP IN THE UK ${ }^{*}$
}

Globally there are many innovative, citizen driven initiatives at grass roots level which are aimed at invigorating local politics and improving public service provision (www.oneworldaction.org/indepth/pro. ject.jsp?project.209). There has also been recognition that civil society rather than public bureaucracies are capable of providing public services and satisfying social needs. Devolving leadership and innovation from bureaucrats to grassroots individuals willing to create and lead projects or organisations to solve social problems and fulfil public purposes is becoming a key feature in many states (Van Ryzin, Burgrud and Di Padova, 31st May, 2007). Indeed the Sloan Foundation in the US since 1997, at least, has sponsored numerous citizen driven projects to foster interactions between citizens, municipal managers and elected officials to assess and improve their own communities. There are examples worldwide of strategic plans being developed by citizens driving the systems to achieve desired results, by performance reporting of council municipalities and service contractors and making them more accountable for service provision (Epstein and Fass Associates, New Jersey, 2007).

\section{Keywords: local strategic partnership, local government, regional policy}

Across Europe, and notably in some Scandinavian countries, urban leaders are mobilising diverse networks of actors, in agenda setting, resource mobilisation, task accomplishment and performance management and measurement (Back - Haus - Heinhelt - Stewart, 2003). Citizen Driven Governance is therefore not a new phenomenon, as witnessed in some Nordic countries with 'free commune experiments', or in Eastern and Central Europe where autonomous local government has been reconstructed. Both illustrate decentralisation of tasks and responsibilities from central to local state level, and even in highly fragmented southern European states or the Federal states of Belgium, Germany and Switzerland, central and local government relationships are altering with the advent of privatisation, contracting out or greater mimicry of the private sector. The role of local leadership and the re-orientation of state and non-state forms, together with various initiatives to strengthen the role of citizens (local referenda in Germany, consultation panels in Denmark, Citizens' Juries in the UK) have all challenged the representative nature of local governance and are affecting local leadership.
It is within this backdrop of global changes to local leadership that this paper will examine the important and relevant gaps in knowledge over how to lead the vital change processes in local and regional regen. eration to the benefit of all stakeholders. In a January 2006 speech to the New Local Government Network (NLGN), David Miliband, the then UK Minister for Communities and Local Government made the case for the practice of empowerment, which was a follow up to a 2005 speech in which he had stressed the importance of the politics of empowerment. Both are seen as challenges to the improvement of local services and bridging the gap between citizens and the democratic processes. Underpinning proposals for new and improved mechanisms for neighbourhood renewal are the notions that citizens can influence service delivery by articulating choice, having improved voices, and re-invigorating local democratic processes. The substantive argument is based on five key elements, thus (i) there is a power gap between what people can do and what the system allows them to do, (ii) decision making should be devolved beyond the town hall to neighbourhoods 
and individual citizens, (iii) subsidiarity is the primary driver of reform, (iv) empowerment takes many forms, and finally ( $v$ ) all four, aforementioned elements are dependent on the nature of the relationship between the central and local state.

This paper takes each of the five elements in turn by examining some of the potential difficulties that could arise in the creation of new forms of UK neighbourhood leadership and management. It also draws on findings from recent Government reports and White Papers, in particular the 2006 White Paper 'Strong and prosperous communities" much of the content of which was absorbed into the Sustainable Communities Act and the Local Government and Public Health Involvement Act, 2007and the introduction of Local Area Agreements (LAAs) and Multi Area Agreements (MAAs) to examine some of key problems that need addressing if the aspirations of political leaders are to match the potential realities for those communities they seek to engage. It is argued that decision makers will need to fuse local, sub-regional and regional objectives and appreciate the spatial aspects of service delivery and democratic legitimacy of decisions if localities are to be transformed and prosper'.

As part of the Local Government Modernising Agenda (LGMA) The UK Labour Government has, since 1997, introduced a plethora of policies aimed at developing a long term strategic approach to transforming localities (ODPM, 2004). Embodied within these change processes are the twin requirements of improving the quality of public service delivery and enhancing democratic decision making processes. The latter lies at the heart of the Government's vision for a future local government system, one in which strong collective leadership involves and engages other public, private, business, community/voluntary and third sector partners to produce Sustainable Community Strategies (SCS) by identifying local priorities. Ten years ago, a White Paper had called for a radical refocusing of traditional and paternalistic decision making in local councils and their replacement with more modern and vibrant local government (DETR, 1998: 5). An Improvement and Development Agency (IDeA) Census in 2001 had revealed that $71 \%$ of elected members were predominantly male and $86 \%$ were aged 40 years or older.

As can be seen from Figure 1, community leaders across the globe now have to make decisions within changing, multi-spatial and interactive spheres of governance.

Indeed as Agranoff and McGuire point out, leadership takes place in multi-organisational, multi-governance, multi-sectoral, and hence there is a need for multi-strategies, multi-visions and multi value forms of governing and promotion of regional (local, author's italics) development (1999). Moreover, Sotarauta suggested that leaders not only lead within organisational and community boundaries but across boundaries to reach spheres in which actions and words can influence, despite having no authorisation. Networks of a variety of individuals, coalitions and capabilities interact in the achievement of joint, separate and collective (authors' italics) aims (2005).

Figure 1

\section{New Arenas of Interactive Leadership} and Governance

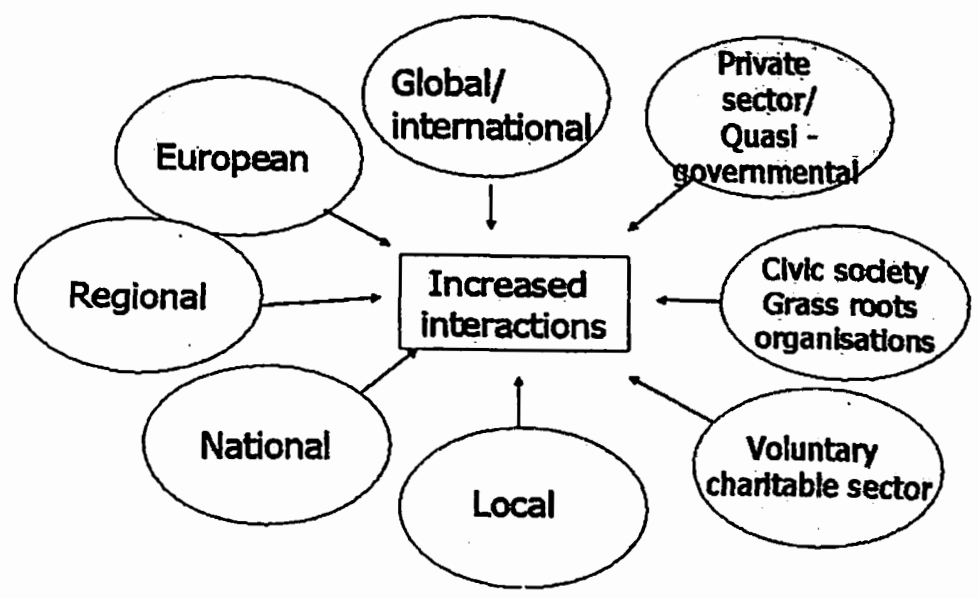

In the UK, Local government has been encouraged to work collectively with partners to demonstrate continuous improvement and to facilitate this Comprehensive Competitive Tendering (CCT) of local services was replaced by the Best Value Regime (BVR), and then in 2001, the inroduction of CPA (Comprehensive Performance Assessment) ${ }^{2}$. Key elements of BV and CPA were the capacity to engage a wide range of stakeholders, notably local community interests (Martin et al., 2005) in long term relationships, as exemplified in Figure 2.

Figure 2

Leadership within co-governance

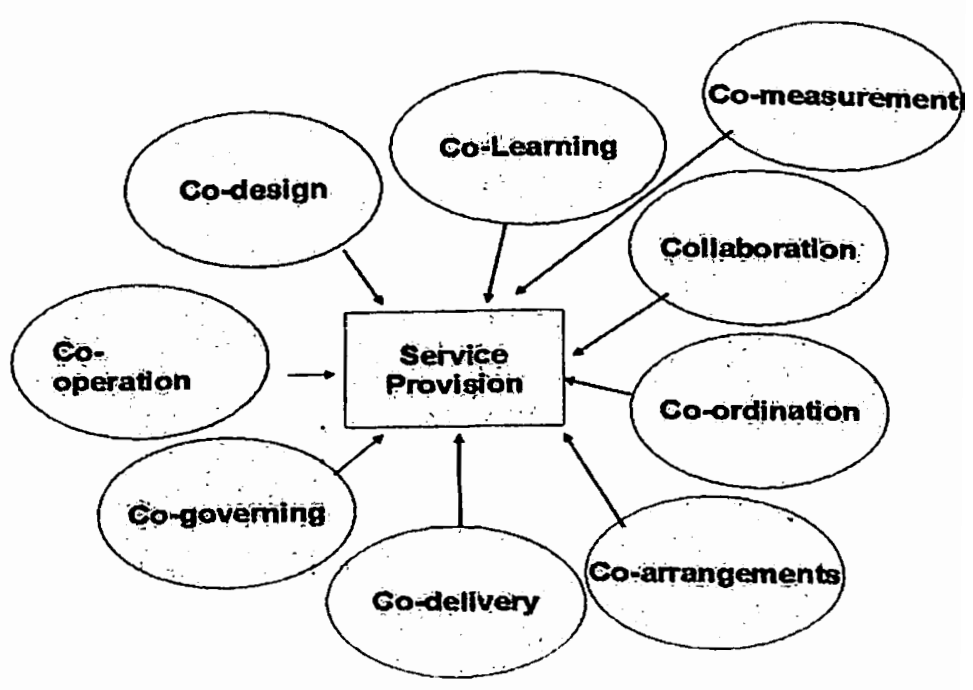


In the recent past, all local authorities were ranked by Audit Commission on five categories (excellent, good, fair, weak, poor), but the balance of these categories was altered and a new criteria 'direction of travel' assessed how well a local authority had gone towards achieving objectives set in previous assessments. Overall the CPA regime still identifies under-performing local, and judges which ones are likely to need direct support or intervention for instigating turnaround strategies (Audit Commission, 2005). It also identifies excellent local authorities where 'freedoms and flexibilities' can be adopted but from 2009, with the introduction of CAA they will be assessed on four criteria (i) Risk Assessment, (ii) Scored Use of resources, (iii) Scored Direction of Travel, and (iv) Performance Data on national indicators, such as police, fire, community safety, education and health.

As Figure 3 shows how over a protracted period Local Authorities have been encouraged to move through a spectrum of Communication-Consultation-Co-planning, design, delivery and measurement, typified in the process of establishing Local Area Agreements and with, it might be argued, a natural move towards more personalisation of services.

Figure 3

\section{Communication-Consultation-Co-planning design, delivery and measurement} (Adapted from Martin, 2003)

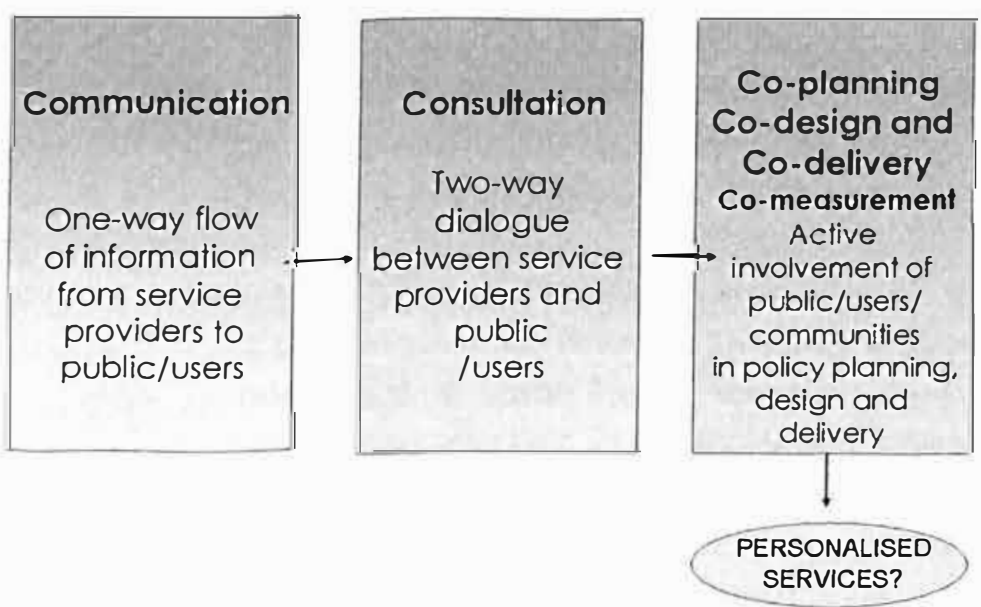

\section{Local Area Agreements}

Local Area Agreements (LAAs) were introduced in July 2004 as part of the wider modernisation and localisation agenda for public services, to deal with cross -cutting issues, initially in county tiers, but then rolled out in collaboration with all partners in two tier areas. They were piloted in 9 areas, followed by 66 in the second round, and now rolled out to all unitary authorities. They are a 3-year agreement setting out priorities for a local area between central and local government partnerships. If local areas perform to HM Treasury floor targets, and achieve 'stretch' targets, or performance above what would be expected for a similar sized local authority they will be given freedoms and flexibilities in how they can use central funds (ODPM, 2004). Pump priming and performance related funds were available through Local Public Service Agreements, but these have largely been absorbed into LAAs. Moreover LPSA 21 was recently introduced to encourage local areas to 'involve' communities of interest in decision making and to enhance community cohesion. A 'Community Cohesion and Conflict Resolution' toolkit (2008) has been developed to assess community engagement, and an 'equivalence tool' will determine whether a service has achieved outcomes, provided evidence to support such outcomes, and show how services have added value.

LAA s were hailed as the mechanism to 'achieve more effective delivery of public services locally', and to 'provide a framework for the relationship between central and local government '(ODPM, 2004:5). Partners in each area were expected to focus on shared outcomes and to simplify funding mechanisms, as well as devolving decision making away from Whitehall and Westminster. The declared aims were:

- To develop a framework for intelligent and mature dialogue between central and local government,

- To allow flexible use of resources at local level to achieve shared outcomes,

- To improve local performance,

- To align funding streams, reduce bureaucracy and transactional costs, and

Figure 4

\section{A typical Local Strategic Partnership: Agency/Actor Involvement}

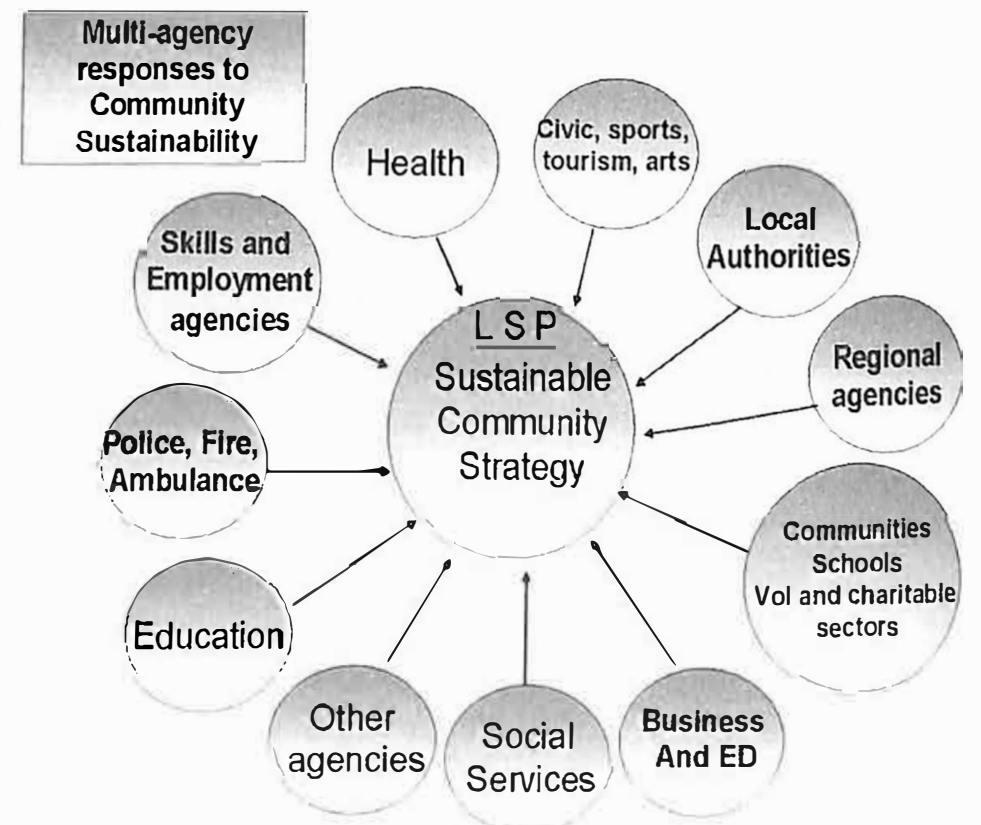


- To enhance the community leadership role for local authorities and enhance joined-up decision making at local level (ODPM, 2004).

Local Strategic Partnerships (LSPs) had been created after 2001 (initially in 88 very deprived areas of the country, but then rolled out to 360 local government areas) and their role, which was to strategically determine local priorities, was strengthened to promote the requisite collaborative working and draw in partners to develop the Sustainable Community Strategy (SCS), as shown at Figure 4.

The Local Government White Paper 'Strong and Prosperous Communities' (2006) had hinted that LSPs might take on the status of a statutory body for the local area, but once the White Paper was absorbed into the Local Govern-

Direct quotations from the 2006 WP

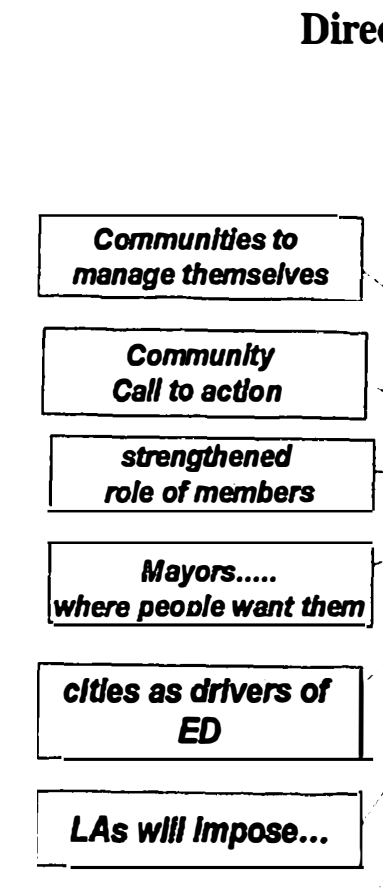

driving up standards

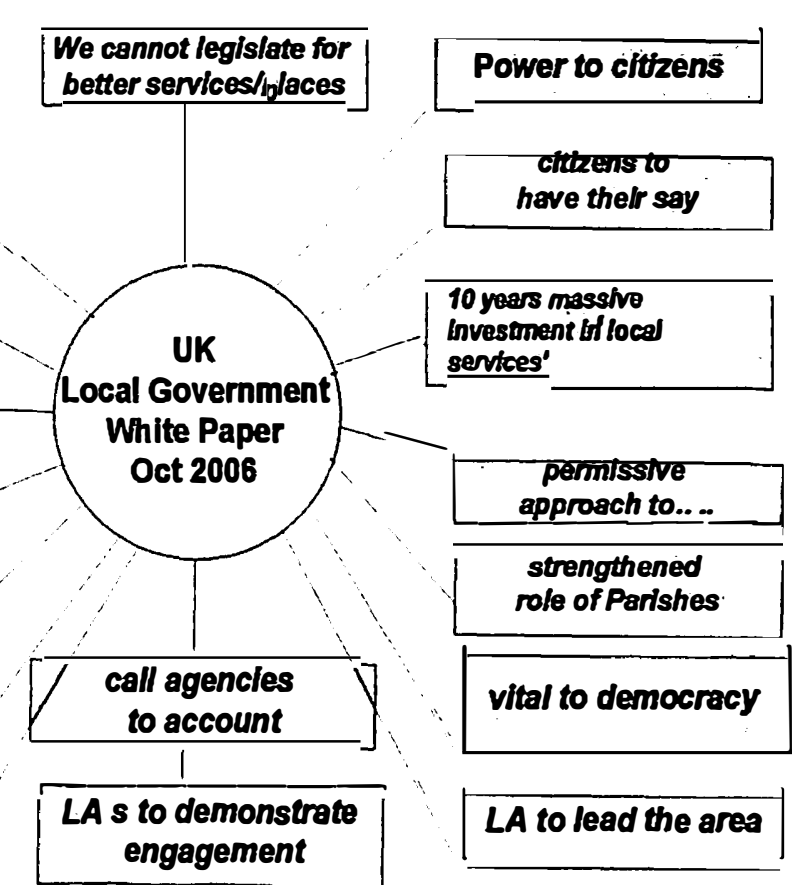

Strong and prosperous communities: The Local Government White Paper, October 2006, Cmnd 6939 ment and Public Health Involvement Act, 2007, the Sustainable Communities Act, 2007 was on the statute books and the Sub National Review of Local Economic Development and Regeneration was unveiled it became evident that the UK Government was creating an infrastructure to align local, sub regional and regional regeneration at the various spatial levels. Though LSPs have not yet become statutory bodies for their areas, the LG and PHI Act 2007 did create statutory Health and Well Being Partnerships as Local Authorities took over many health service roles, and absorbed the work of Primary Care Trusts into LSP activities. Moreover, Local Authorities are still the responsible body for their local areas, they still provide the secretariat for both LSPs and LAA partnerships, and funding is still channelled directly through them, as the accountable bodies. They were given an enhanced scrutiny role in the 2006 LG White Paper, and the LG and PHI Act, 2007 and now have the capacity to act on behalf of communities who challenge local agencies under 'Call to Action', once an agreed petition is submitted. Figure 5 provides a selection of 'quotes' from the 2006 White Paper to demonstrate just how much the focus was on community involvement, and indeed in 2009, Local Authorities have a new 'duty to involve'. Moreover, the Sub National Review of LE and Regeneration gave JobCentre Plus, Regional Development Agencies and Learning Skills Council a statutory duty to co-operate' with Local Authorities to determine improvement targets for an area, as well as requiring other agencies to

have a 'duty to have regard to targets', in particular with regard to Multi Area Agreements, across local authority boundaries for particular regional and sub-regional collaborative ventures and programmes.

Furthermore, within regional and local economic development, local authorities now have an enhanced role in scrutinising the activities of Regional Development Agencies (this role was formerly the responsibility of Regional Assemblies, but the government announced their abolition after 2010) and of taking the sub-regional lead in determining how local development and regeneration feed into new Integrated Regional Strategies.

At the beginning of the LAA development phase, all local partners in every local government area were brought together to determine LAA priorities but initially, at least there was confusion and ambiguity on how exactly they would work. Their aim is to allow greater flexibility and freedom in finding solutions to local problems and to deliver better outcomes through improved coordination. Each LAA has four broad 'blocks' ie 'Children and Young People', 'Safer and Stronger Communities', 'Healthier Communities and Local People' and 'Economic Development and Enterprise', but some areas have 'single pot' status. In some areas, at the early stages there was an attempt to shoehorn 350 targets into these 4 key target areas, and this created considerable conflict and debate (County Durham LAA Partnership meeting, January 2006, at which this author was present). 
NB. Appendixes 1 and 2 show the New Performance Framework (NPF)

The Outcomes-Targets-Indicators Framework

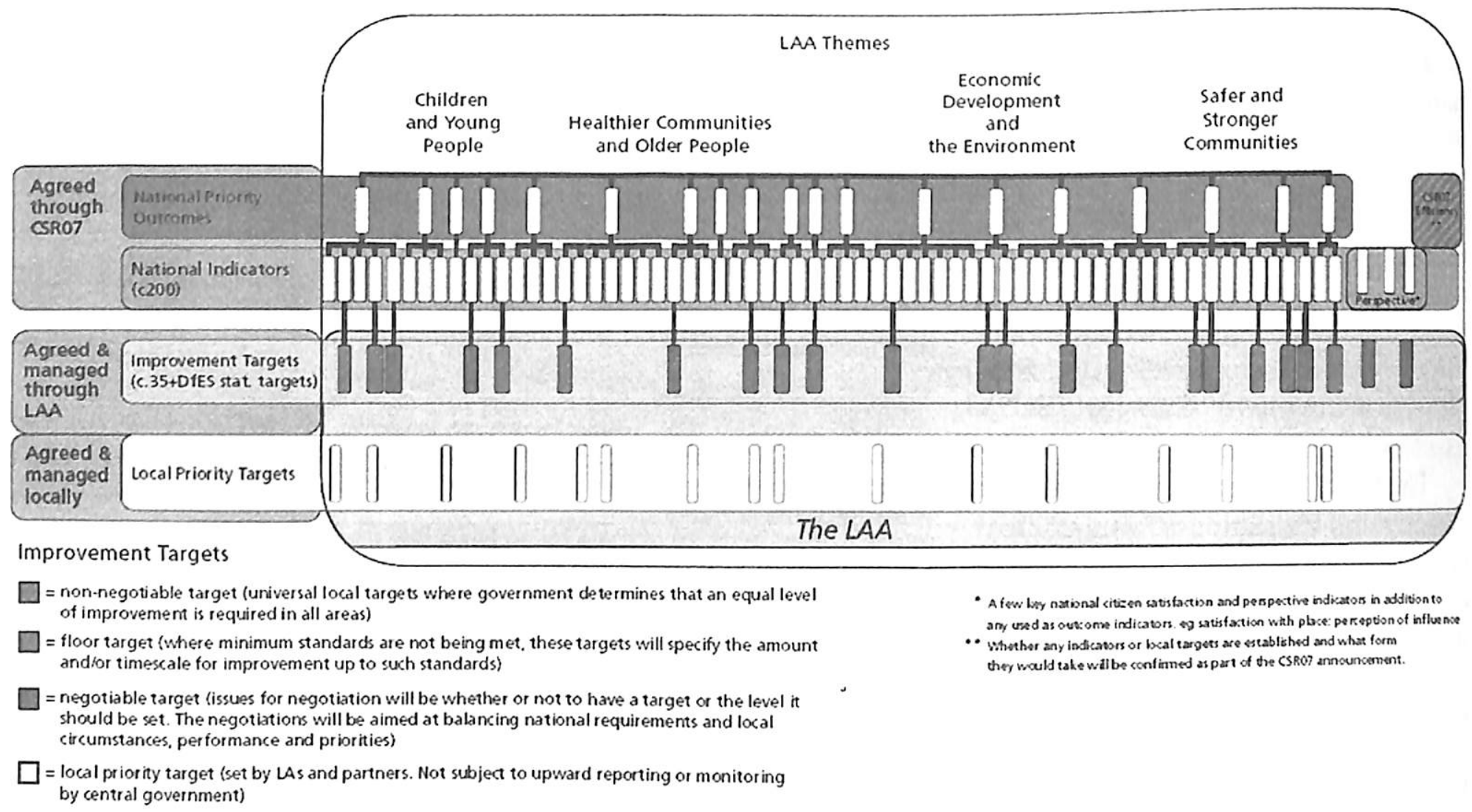

New Performance Framework

Appendix 2

\section{NATIONAL INDICATOR SET (200) AND LOCAL PRIORITIES}

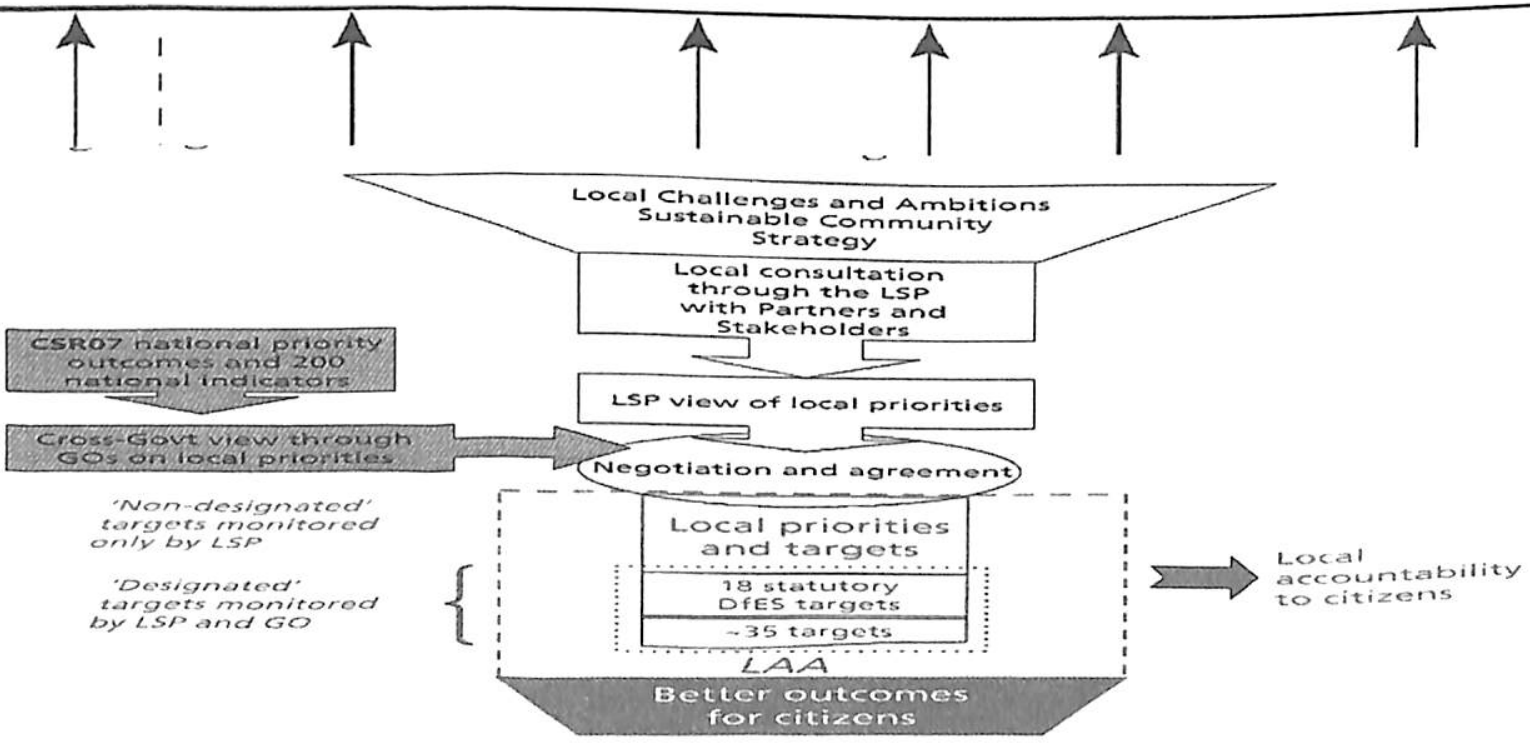

LOCAL FUNDING SOURCES

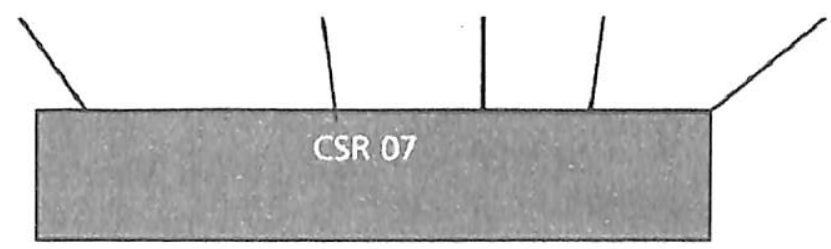

Unringfenced 
Many Local Strategic Partnerships had taken two to three years to develop and engage relevant partners, and some had experienced great difficulty in involving business and community representation (Liddle - Townsend, 2003). Moreover, the differences in socio-economic and political profiles between localities, objectives and working arrangements created time consuming and fraught processes in pooling activities, funding and targets into overall LAA targets.

The Local Government White Paper (DCLG, 2006) had confirmed LAAs at the centre of a new performance framework for local authorities, but at that time little consideration had been given to how the new regime would be delivered. There was limited advice on which stakeholders to 'involve', which one would lead the process, or possess the capacity to drive a 'whole system' approach to regeneration. A New Performance Framework for Local Authorities and LA Partnerships was announced as part of the CSR 2007 and confirms the establishment of 198 indicators $^{3}$ plus 17 statutory targets on educational attainment, for all single tier and county council Local Strategic Partnerships (LSPs). Of these 198 central targets, localities will negotiate 35 locally agreed indicators, based on local LAA priorities.

\section{According to the Minister, Hazel Blears}

'We will shortly consult on the technical definitions of the indicators, giving stakeholders the opportunity to give views on the methodology, frequency of reporting, and data source of each individual indicator' ( $\mathrm{Ha}$ zel Blears, October, 2007)

Local Strategic Partnerships (LSPs) LSPs will deliver each LAA by bringing local authority partners ${ }^{4}$ together to identify local problems, influence local priority setting, and determine how funding will be spent. Sustainable Community Strategies (SCS) had already been developing in all local authorities, but their effectiveness was questioned. LAAs were a reaction to the failures of SCSs and will provide baseline information on current performance, develop indicators and targets for improved performance, and pool existing funding resources to specific outcomes.

Funding is by $A B G$ (Area Based Grant) and additional funding can be drawn on, such as NRF (or its successor WNF and DWP DPA combined), mainstream funding, or other externally granted funding. Rules apply as to how funding can be pooled and aligned, and after 2009 councils will have complete flexibility over local spending decisions, thus potentially ending the prescribed four blocks. Funding will be unified thereby leading to more integration and cross cutting approaches.
Evaluations on the early impact of LAAs to date have shown that their potential in bringing about a transformation in both governance and the delivery of services to address cross-cutting outcomes is far from clear. Furthermore, whilst the 2006 Local Government White Paper placed LAAs at the centre of the new performance framework for local authorities, there is an ambiguity over how far LAA performance management, governance and accountability systems should be capable of bearing the weight of the 'whole system' of local delivery vis a vis bringing about a smaller number of outcomes. Indeed, it has been reported that effective mutual accountability between partners has also proven hard to embed given the democratic accountability mechanisms of local government, the network processes of sector groupings, and the managerial models of other public sector partners. Though there is a 'duty to cooperate' placed on key named partners, LAA involvement is still largely voluntaristic and alignment and pooling of funds will still be based on trust and informality, rather than contract.

Government Office (GO) negotiates with local areas on how well outcomes, indicators, and targets contribute to national, regional and local priorities, how funds are aligned and freedoms and flexibilities determined. All will contribute to presumed competence and devolved autonomy. GO also have responsibility for performance management, as well as six mandatory Neighbourhood Renewal (now Working Neighbourhood) outcomes. Existing performance monitoring mechanisms for Neighbourhood Renewal Fund (NRF), which from late 2007 was been transformed into a new Working Neighbourhood Fund (WNF) and combines DWP (Department of Work and Pension, Deprived Area Fund, will also alter when freedoms and flexibilities in LAAs are awarded, and there will be a reduction in monitoring and reporting requirements. Freedoms and flexibilities will be negotiated between local partners and LAA s can pool funds (minimum pooling, issue based pooling or extensive pooling) from central government; to carry over a reasonable level of unspent resources from one financial year to another; to reduce monitoring and reporting requirements; freedom to vire some mainstream funding between organisations to meet shared LAA outcomes. Furthermore, additional locally rooted freedoms and flexibilities will enable local authorities and LSPs to present a business case underpinned by strong evidence to support better working practices and improved service delivery. A Reward Element allows LAA partners to gain even greater resources if they match certain agreed 'stretch' targets and PPG (Pump Priming Grants) are also available. 
Local Strategic Partnerships (LSPs) role was to be strengthened to promote the requisite joint working and as the aforementioned discussion shows, there have been numerous measures aimed at improving service quality and ensuring that the gap between the governors and the governed is bridged. Some of the more notable ones will now be examined, although this new form of governance arrangements, as will be seen later in the paper, has thrown up a host of problems.

\section{Is there a power gap between what people can do and what the system allows them to do?}

When the UK Labour Government launched a debate on the shape and nature of local government, in its New Vision for Local Government (2004) it anticipated that the ensuing discussions would feed in to a 2006 LG White Paper, Sustainable Communities Act and Local Government and Public Health Involvement Act, 2007. At the heart of the debate is the view that people must be empowered to help to shape public services, use their knowledge and capacities to shape their own lives and communities and bridge the power gap between local government and those communities it serves (2006:3).

The starting point, was, according to Miliband, the former Minister, that devolving decision making should be as close to people as possible, as the following quote illustrates:

'There are three key virtues that mark out the best of local government; excellent, value for money services, strategic leadership of the area and empowerment of citizens. Empowerment is about the ability of people to have a real say in decisions that affect and shape the course of their own lives' (Miliband, 18.01.06, NLGN)

It is not clear, however, whether the government's reliance on the institutional design of local partnerships and commitment to devolved decision making sufficiently robust to deliver on its ideological aspirations in relation to community driven regeneration. An earlier document 'Citizen Engagement and Public Services-Why Neighbourhoods Matter' gave many positive examples of current best practice on neighbourhood management, neighbourhood charters and delegated budgets. So far, so good, we might argue, and the plan to develop Neighbourhood Agreements in the 2006 White Paper was a step towards getting local authorities and communities to sign up to agreed targets. Despite the rhetoric of local people taking control of decision on their areas, the Government also suggests in Vibrant Local Leadership that ward councillors should be the main link between service provision and local communities. There are mixed messages in the government's agenda, because on the one hand, individuals and local community interests are being urged to join Neighbourhood Forums, especially LSP s, and in some cases local authority members have been actively discouraged from attendance. On the other hand the Government wants local members as champions of local causes. This ambiguous role for local members as champions of local areas, and the need for individual or other collective voices resonates throughout the documentation.

Good practice examples exist where communities and their representatives have been effective in 'Calls to Action' or other neighbourhood solutions to problems. They are held up as 'ideal' forms of governance, but questions still remain on capacity, especially what types of skills are needed to engage in neighbourhood management. This is particularly true as new roles and responsibilities are taken on with the changing statutory basis of existing 'informal' and 'hitherto 'collaborative' forms of decision making. If we are to move beyond engaging the 'usual suspects' then more thought needs to afforded to the expectations being placed on those being urged to manage and govern their neighbourhoods.

\section{Devolution of decision beyond the town hall to neighbourhoods and individual citizens: Some difficulties}

In Empowerment and the Deal for Devolution (2006), both terms 'empowerment' and devolution' are used inter-changeably to mean Local Area Agreements as a means of co-ordination between central government and local government, devolved decision making and shared outcomes. As an afterthought however, the document suggests "citizen involvement is central to determining local priorities' (page 5). It is very ambiguous, and the document confuses the role that local government has vis a vis communities, in particular where conflicts may arise. The idea of empowerment and devolution appears to mean that local government and communities will help central government achieve targets and pre-determined outcomes, rather than being concerned with how local actors can determine their own local conditions within central policy developments.

Although the document suggest 'Central Government needs to re-look at balancing the performance framework, so that bottom up pressure from citizens can be matched with reform of top-down accountabilities', the solution seems to be, in the same paragraph, 'local government needs to share more power with citizens'(?) Paradoxically the Minister says that there will continue 
to be national standards to reflect Government's priorities, citizens will be able to challenge through citizen power' but ' top-down controls such as inspection will be used ONLY where the citizen is unable to monitor and control'. Empowerment in the documentation is taken to allow citizens a partial role in challenging predetermined targets, but little in this document refers to real democratic input, though there is a lot of rhetoric on increasing the voice and choice of citizens. What choice do they have, what voice do they have? These are not clearly stated, and rather than emphasise real citizen control, they are urged to challenge service deliverers in the role of consumers of service only.

Bottom up pressures will come from falls in satisfaction, it is argued, and therefore the capacity to trigger external challenges, re-tendering services, and publishing local service agreements' Nothing in either of these two points suggest complete local power and control. This is simply challenging of service delivery, and nothing about how the services were shaped at the beginning. Participatory methods of consultation and decision making are acknowledged, but no where is there any thought given to the mechanisms for communities to exert this power, other than to challenge service delivery and targets, notably to challenge local government and not central government!!

Central government's arguments rest on the notion that if citizens individually or collectively have the knowledge and capacity they can bridge the gap between what they can do, and what the system encourages them to do. This is referred to as the power

The future role of the Third Sector in delivering local regeneration: Commissioning

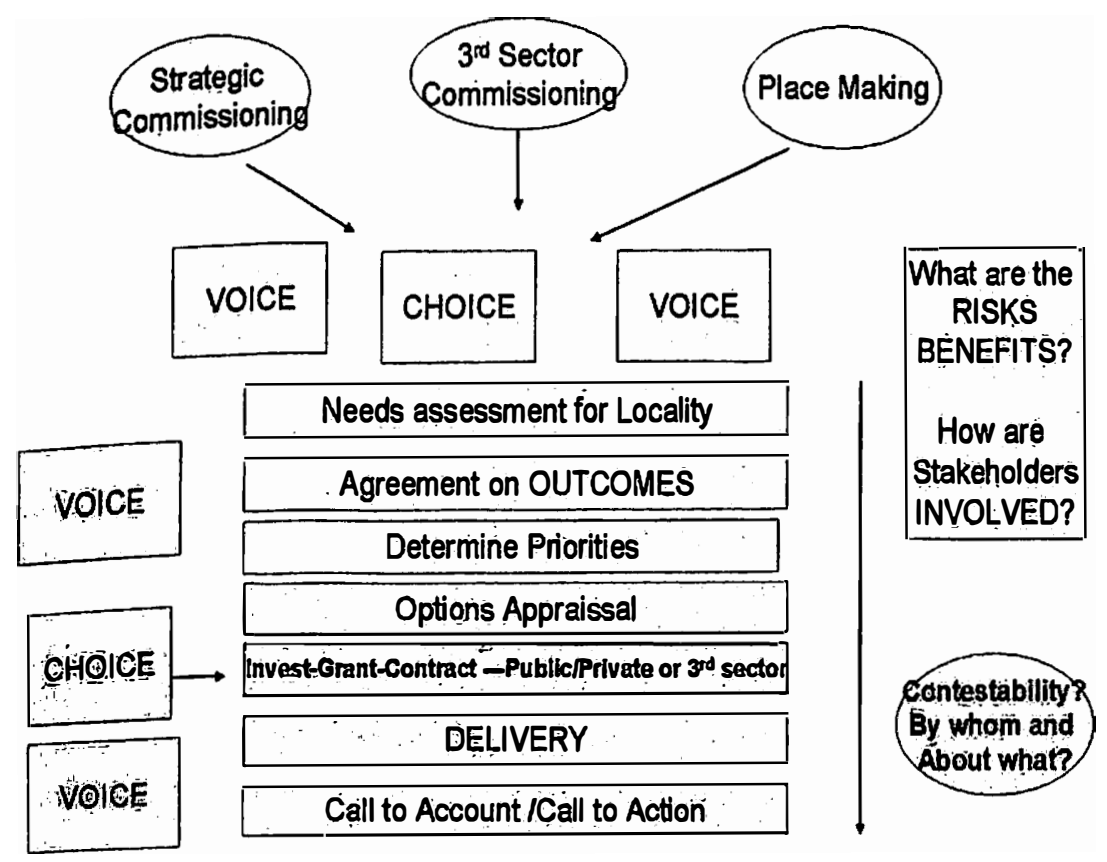

gap, but there is no expansion of the concept or any suggestions at all, either in what citizens want to do, or in fact what the system encourages them to do. We are left at the end of the paragraph 'up in the air' with a woolly notion that citizens want more power, local authorities need to give them more, but at no time are any examples of real conflict and challenge articulated. Significantly there is no suggestion anywhere in any of the policy documents that central power might have to be weakened!

Central Government is keen to devolve power to neighbourhoods and citizens, if the raft of documents emanating from Westminster and Whitehall are a testament to that, but there are many governance issues to overcome. It is still not clear whether LSP s should remain thematic as they are at present, or whether they should be clustered around, and reflect LAA targets. The co-terminosity of other partners, and the relationship they have with LSP s has yet to be determined, and the use of Single Delivery Vehicles as a means of commissioning activities on behalf of an LSP needs further thought and discussion. There are already examples of where SDVs or Single Delivery Partnerships have been used (eg. in Liverpool) but they are at a very early stage of evolution, and not been in operation long enough to measure the real effectiveness.

Parallel changes in establishing the Office of the Third Sector in the UK Cabinet Office has shifted the focus of commissioning local services towards the third sector, and in the next two to three years there will be a move towards training up 2000 commissioners with

Figure 6 the objective of establishing a system to Strategic Commissioning, as indicated at Figure 6. The need to engage 'voices' in making 'choices' is core to this new model and focuses the minds on what choices should be made on either further investment in a locality, a grant or a contract to be awarded to any combination of public/private or third sector group/ agency/individual (Figure 6).

The relationship each LSP has with its sponsoring local authority and the partners represented on the forum vary in different parts of England, and no one model has emerged as the 'best way' of organising and relating. The government did consult widely on the idea of placing a statutory duty on LSP s to work more closely with the local authority, but as yet it is reliant on 'duty to cooperate' and the forthcoming 'duty to involve'. Further- 
more, as each LSP is a mix of statutory and non-statutory bodies there is, as yet, no obligations or duties placed on any representative body who attends the LSP meetings. Community engagement has been piecemeal, and so far no one body has taken on responsibility for engaging communities of interest (especially those hard to engage voluntary and community, or business and commercial sectors), other than the efforts of local authority officers or members who either chaired the initial LSP meetings, or provided the secretariat. Central Govemment proposed Neighbourhood Agreements, but these will not remedy some of the acute accountability problems that have arisen, and will continue to blight the activities of LSPs. Most LSP s have developed their own protocols (but largely dominated by local authority committee type arrangements) and hardly any have determined specific partnership arrangements, or whether the assessment of LSP activities needs to include partnership working. In some areas of the country local authority executive members have involvement on LSPs, in other less so, and there is a big question over the role of backbenchers in engaging communities of interest, or scrutinizing the activities of LSPs. Little thought has been devoted to how and who will measure LAA activities, and the mixture of NRF(WNF) LSPs, non-NRF(WNF) LSPs, various regional, sub-regional and other partnerships not part of LSPs, and local authorities involved. The difficulties are compounded by individual and agency representation from both statutory and non statutory bodies, which all adds to a confusing picture of local governance. To complicate things even further mainstream funding agencies are expected to match some of the LAA funding pots, and this muddies the waters further with regard to accountability and performance management frameworks. The variety of both between contributors to LAA and the linkages has become ever more opaque.

Capacity issued have long been recognised as a significant factor in the overall success, or otherwise, of any neighbourhood governance and management, and many LSP have engaged external consultants to help build up skills and knowledge bases. There are also countless support mechanisms to engage or foster community participation, reflected in toolkits, guidance or other learning opportunities. However, none of these will succeed if political skills and information sources are lacking. If LSPs were to be given a statutory basis and be capable of commissioning external activities, or were to become the main source of delivering the agenda, existing skills bases need augmenting. As previously suggested it is likely that strategic commissioning will involve third sector agencies and actors. This will all rest of what the exact nature of LSP $s$ will be, and what responsibili- ties contributing partners will undertake. Creating Sustainable Community Strategies will require even great breadth of skills and knowledge, but engaging with external agencies in commissioning work requires a more sophisticated set of skills than hitherto developed.

One of the most contentious aspects of the plans for empowerment and double devolution is the fact that there is a clear recognition of the need for reform at the Centre (page 17) and an acknowledgement that there must be more transparency on targets, interventions, underperformance to drive up standards, but the focus is placed firmly on local and not central government and Whitehall. The Minister suggests that it would be foolish to abolish national mechanisms for managing and monitoring performance, but all the changes are focused on how citizens can bring local authorities to account. There is nothing to suggest that some of the problems may lie at the doors of both Westminster and Whitehall. Subsidiarity, which will be discussed next, is regarded as a core element to drive the reform agenda, but like all the other woolly concepts, is problematic and contentious.

\section{Subsidiarity as a primary driver of reform}

Subsidiarity is seen as key to reforming local governance, and the National Neighbourhood Agreement was hailed as the bedrock of this change. There is an expectation that central and local government will 'sign up' to these agreements, but nothing in the documentation suggests either individual or collective community 'voices' to be heard in this process. Subsidiarity is taken to mean 'Devolving as far as possible'(page 12), including devolving budgets, information', and there are examples of cases where rewards have been given for initiatives such as, Partners in Policy Making, Disabled youth in the NW, West Sussex Adult Care, NHS Expert Patients Programme. All are hailed as having exemplified 'responsible behaviour, but this begs the question of what exactly 'responsible' means in this context. Is it merely an acceptance of behaving responsibly in meeting central targets, or does it have another meaning we aren't told about?

It might be argued that' subsidiarity' in this context means that local authorities obtain 'earned autonomy' if they achieve central targets. Through the CPA (and CAA to come) and LAA mechanisms greater flexibilities and freedoms will be bestowed on them, but there remains a question on how much tolerance to local differences will central government allow, given the stringency of HM Treasury targets, anticipated outcomes and impacts of policy. 


\section{Forms of empowerment}

Empowerment will be facilitated by extending Neighbourhood Management, through the Respect Action Plan and getting local authorities working together with neighbourhoods. There will be a right for local people to trigger inquiries into local issues, 'Call to Action' for award councillor to bring police to account if they have not sufficiently responded to community concerns( and this has Chief Constables, Police Authorities and local members very concerned, particularly as Crime and Disorder Partnerships may have their activities placed under the aegis of LSPs, and local authority members will be responsible for scrutinising the work of CDPS), neighbourhood policing, petitions forcing issues on to local council agenda, satisfaction surveys, delegated budgets , councillors have $€ 10,000$ per annum for local projects determined in line with local people. It is not clear whether this figure of $€ 10,000$ is per councillor, per ward, per local authority, and how the sum will be awarded, and by whom? Neighbourhood charters will be drawn up to get service providers to keep neighbourhood clean and tidy, and under the 'Community Right to Buy Out', tenants associations will be able to gain formerly owned local authority assets. This is particularly worrying Fire and Rescue Services, and there are incidences of parts of Fire Stations being bought out by communities to host community events and LSP meetings ${ }^{5}$. Parish councils will have a larger role to play in local issues, than hitherto evident, and they will have greater rights to representation and the ability apply fixed penalty notices. Many of these new community powers seem excellent on the surface, but as the police, fire and rescue service and local ward member examples indicate, none are without inherent difficulties and conflict.

Some examples of different forms of empowerment are illustrated in the documentation, with case examples to show how direct payments can be made to communities, or where individual budgets have gone to neighbourhood management, examples of 'better' forms of consultation (better for whom?) and local authorities will be able to 'reward' neighbourhoods that to take on a new, active role in design and production of services. The questions to be asked here, are 'do all citizens want to take an active role?', 'who determines the payments should be made?', 'who has determined what a better form of consultation is?', 'will local communities be rewarded for designing and producing services in line with what central and local government wishes them to, or will they be rewarded if they come up with more innovative, but maybe more expensive solutions to service delivery?'. Mother and apple pie springs to mind, when we think of the overall costs of service provision when it is delivered by local authority officers or their partner organisations. There is little evidence to suggest that if communities are involved in designing, delivering or measuring service quality that they will come up with radically different approaches, nor is there sufficient evidence to suggest their options may be more economical and efficient. It seems that central government may well wish to push decision making down to the lowest level, but it remains to be seen what the response will be if local communities started to spend money unwisely or became even more inefficient than traditional suppliers. Will central government show tolerance to local solutions, if they are out of tune with central dictats?

- All the proposed budgetary changes, with supposed devolution to local communities, and an enlarged role for parish councils, will require statutory changes to the way local governance is conducted, because even LSP $s$ have funding paid into them via the Responsible Body, mainly local authorities. Moreover, has any thought be given to the fact that this is a challenge to the power, and authority of elected members, or that given the 'representative nature' of current system, we need to rethink 'deliberative' and consultative' forms of democracy, and develop new forms of accountability. Multi Area Agreements, which are not the central focus of this paper, but which are expected to involve multi-partners across sub-regional and regional joint programmes must demonstrate that they have agreed democratic accountability mechanisms in place. However, as very new forms of organisation/partnership, there is so far little in the way of Government guidance, so it is difficult to discern how these partnerships will either operate or be measured on adding value. They are meant to be collaborative, localised, flexible, voluntary and informal agreements that act as catalysts for cross boundary issues; ones that involve agreement on shared targets and between key players across subregional and regional boundaries. Their primary objective is to add value to the work of LAAs and improve well being and sustainability.

\section{The nature of the relationship between central and local state}

The new central-local relationship, has according to all recent Community and Local Government Ministers, at core, the idea that empowerment of citizens is vital. As local people hold local government to account 
for the services it provides, then 'national government should change its accountability structures'(page 9). The strength of bottom up accountability goes hand in hand with reform of top-down accountability, in terms of targets inspection etc, to ensure that it is 'proportionate' and 'risk based'. We need to ask' How can we improve things at local level, and empower local people and local government to find their own solutions' however, nothing at all on how Whitehall structures, processes or procedures might change as result of these reforms? A recent Central Local Government Concordat (December 2007) outlined the rights and responsibilities of central and local government. Thus:

- Central Government has responsibility and mandate to manage national economy, Public Service improvements and standards of delivery.

- Local Government is responsible for service performance, well being and cohesion.

- Whereas both Central Government and Local Government have responsibility to use taxpayers money wisely and engage citizens in shaping delivery. LAA $s$ are regarded as this new style of negotiated governance to involve and engage citizens and other interests.

The concordat goes on to say

- Central Government has the right to set standards, the right to intervene to ensure performance, and the responsibility to consult with Local Government, remove obstacles, reduce burden of guidance and regulation. Local Government has the right to address community priorities, deliver Public Services, and shape the future without undue interference, but has the responsibility to provide accountable leadership, visible, responsive and work collectively with business, third sector and other partners.

As this indicates, central government is keen to maintain control of the devolution process, despite declarations to the contrary. Enshrined in this concordat is the right of central government to set standards and intervene when performance is below par, but it is also local government's right to shape the future of local areas 'without undue interference'. This example of double speak is characteristic of recent policy documents.

The mechanisms for funding local authorities mainstream activities has also changed in recent past, as the Standard Spending Assessment, based large on historical and population data, became the Formula Spending Share(FSS), and the body that negotiated spending changed from the Consultative Council on Local Government Finance (CCLGF) was transformed into the Central Local Government Partnerships (CLGP). Lo- cal authorities were also given new powers to promote the economic, social and environmental well-being in their locales as well as creating LSPs (Local Government Act, 2000), and ODPM's Ten-Year strategy for local government, 2005, strongly endorsed a community leadership for ward councillors to take on strategic role on behalf of their local area (ODPM, 2005).

Central Government is set to continue its modemisation and improvement regime, and for the foreseeable future, at least, CPAs (CAAs) and LAA s are set to continue as forms of scruntinising, inspecting and auditing the work of local authorities, but LSPs, and other forums for engaging service users, communities and neighbourhoods will be a strong encouraged to assume greater controls on driving up standards and performance of local authority activities. Services will now need to be more tailored to what service users and communities want and more choice and opportunities for redress of grievance will be made available (ODOM, 2005b). An example of this would be the 'Call to Action' powers introduced into the Criminal Justice field, but now rolled out to all services.

The Audit Commission will increasingly develop what it has called 'strategic regulation', which seeks to reduce running costs and the burden which it imposes on inspected bodies (Audit Commission 2003), and with the support of the Government, the Improvement and Development Agency for Local Government (IDeA) has developed a framework for increased self regulation to take the place of some top down inspection activities (IDeA, 2006). The Government also proposed by 2008 to brigade all of the existing inspectorates into just four agencies covering health and social care; education and young people; criminal justice; and local (authority) services (ODPM, 2005c) but this has since been extended to seven inspection agencies.

The proposal to re-organise local government, and extend unitary local government across the whole of England, changes to the functions and financing of local government following completion of the Lyons Review, and an increasing emphasis of the role of larger city regions as engines of economic prosperity and innovation in service delivery are all potential changes that will affect future governance.

\section{A Case Study example: \\ County Durham Strategic Partnership and the development of the LAA}

This author was present at the first consultation meeting (attended by 140 representatives) to develop County Durham's LAA priorities, and it is safe to say that 
the whole day was marred by confusion on priorities, disputes over territorial and funding arrangements, and petty rivalries. There is no reason to suppose that this scene was not played out in other areas of the country. The confusion arose from trying to dovetail existing policy areas into only 4 key areas (safer, stronger communities, children and young people, healthier communities and old people, economic development and enterprise), and there was much debate around where the rural agenda fitted in, or did priorities for education fit into children and young people's category, or as the business representatives present suggested, into economic development and enterprise. If education does indeed fit into the pigeonhole of children and young where does that leave education for people who are not young (eg for adult education or education for disabled people over 18?). The educational representatives from the LEA voiced concerns that their roles and responsibilities could be subsumed into Childrens' Services, thereby threatening not only their livelihoods, but the services for children who may have opted out of educational provision (those excluded from school or who had chosen to be truants, and who would not then be counted as priorities).

The issue of economic development and enterprise caused the most consternation and debate, as the LAA partners were from vastly different professional backgrounds. The group attempted to fit the targets of the following areas into only ONE key LAA target, with great difficulty, it must be said:

- Unemployed and worklessness, incapacity benefit

- Economic performance

- Business creation, and sustainable businesses

- Skills agenda

- Outward migration of graduates

- Attracting FDI

- Procurement of services for businesses

- Research and Development

- Infrastructure needs to attract businesses

- Social and rural enterprises

- Role of the public sector as a dominant employer

- Best practice between public and private sectors

There was an eventual, and reluctant resolution to the debate, but each partner continued to feel that these issues might fit into any one of the other LAA categories. Furthermore each NRF (WNF) area can bid for a Local Economic Growth Initiative programme (LEGI) and the subsequent SNR of LE and Regeneration created the potential for MAAs and other cross boundary activities. It also created Regional Ministers, introduced a Scrutiny function, and gave prominence to local authorities in promoting economic development, feeding in to the Integrated Strategy and bringing the RDA to account (since government announced the abolition of Regional Assemblies in 2010).

The conflicts apparent in the case materials were no doubt played out in other areas as other assembled 'partners' attempted to bring coherence to a very messy set of policy agendas. Interestingly enough, and despite the fact that one key LAA target is safer and stronger communities, there were no representatives from the Fire and rescue Services or the Ambulance, or NOMS (National Offenders Management Service, consisting of prison and probation services) and this is a perennial problem, given that changes to all uniformed services are going to impact on the work of LSP $s$ and LSP activities will impact on the work of the criminal justice system.

The discussion is outside the remit of this current paper, but there are issues arising from two important reports on reorganisation of both the police and fire and rescue services that need deeper investigation such as the ambiguous roles of LSP $s$ and Chief Constables, Chief Fire officers and specific council members in commissioning services, on overview and scrutiny committees, serving on Police or fire Authorities, and importantly even more worrying (for Chiefs of both uniformed services) the Call for Action proposals, where a council member can act on behalf of communities to bring police and fire and rescue services to account for (Closing the Gap, 2005; ODPM, 2005).

There are numerous unresolved issues in leading a collective leadership approach to local, sub-national and regional change, and the advent of LAAs, MAAs and the forthcoming CAA assessment regime have, in many respects muddied the waters further, rather than simplifying and reducing bureaucracy, which was the declared and intended aim. As well as technical aspects already identified by the Minister, community leaders will need to address, some if not all of the following (in no particular order of importance):

- Leadership capacities, resource intensity and increase in huge workload at all levels in the system. National and Regional Improvement and Efficiency Partnerships have been created to bridge capacity gaps but no clarity on whether they will support LAA development. Will they support MAAs or LAAs? This is far from clear and despite numerous leadership programmes across all sector (eg. Third Sector Leadership, Local Government and Health, Police, FRS, Member Leadership, Regional and Collective Leadership) there is limited evidence to show that leadership 
capacities have been augmented, or indeed that improved collective leadership equals improved local and regional performance.

- Performance management and measurement systems. Are existing systems fit for purpose and agency PMF s suitably aligned? Will new performance regimes evolve or be imposed? What about self assessment or peer assessment? How about a mixture of self assessment, peer assessment, centrally imposed assessment? How will process issues, rather than outcomes and impacts be measured? Will direction of travel be assessed? The Minister has stated that by April 2008 all other sets of indicators, including Best Value and Performance Assessment Framework indicators will be abolished, but it is not clear whether non-local authority performance regimes will also be abolished. This seems highly unlikely, given the complexity. Moreover, there is ambiguity on how LAAs, MAAs, CAAs and other nationally measured policy areas will be either brought together or remain separate. Despite the creation of seven new inspectorates, there is little evidence to indicate that they will be capable of merging activities, given the scale and scope of their remits.

- Use of Information Is it to be gathered at Super Output Area Level or ward level? The relocation of ONS officers to regions and the shift towards data gathering at SOA level has altered the type of information available and the spatial. Sharing of information at the sub-regional level and which agency will have responsibility for collecting and collating information? How will national, regional and locally collected data be stored and shared? No statements have been forthcoming on the issue of data collection and sharing.

- Governance and accountability. Who to involve? How to operate and govern a network of partners who all represent different agencies in the pursuit of common goals? How to deal with conflicting objectives? What exactly to be accountable for, to whom, and in what circumstances? Will Regional Minister become responsible, or will GO work in collaboration? Which agency/individual will be the final arbitrator? What spatial level will dominate in accountability terms? MAAs have been given a direct requirement to develop agreed democratic accountability mechanisms, but whilst they operate as flexible, voluntary and informal forms of governance agreements, based on consensus, collaboration and partnership working but within an existing system of representative government the development of new forms of democratic arrangements will be fraught with problems.

- Linking LAAs to the main tenets of the sub-national review of ED and Regeneraion, especially Integrated Regional Strategies, the role of Regional Ministers and the Regional Select Committees? The Sub National Review points out how economic development is a multi-scalar responsibility but does not go further in suggesting which level of government has the lead in this, other than to say that Regional Assemblies will be abolished, local authorities will be given new powers for ED and scrutinise Regional Development Agencies (RDAs). A collection of local authorities will form a forum to combine the RES and RSS to develop an Integrated Regional Strategy but little guidance on how this process will be operationalised, and which body will take the lead or resolve any disputes.

- Linking LAAs to Multi Area Agreements(MAAs), and Comprehensive Area Assessments (CAAs), which will be introduced in 2009. It is not clear what happens if MAAs are not coterminous with LAAs and as they are voluntary undertakings, how will they fit in with LAA? Moreover, there are still question marks over linking both LSP s and LAAs to executive decision making and scrutiny functions in councils.

- Linking LAAs to the City Region Agenda and to European requirements and demands, as well as the objectives of Urban Development Companies.

- Linking with agencies where priorities are determined by Central Government. Highways Agency, Job Centre Plus, Environment Agency, LSC and other agencies are encouraged to be part of LAAs but with priorities set at national level this will inevitably lead to conflicts of interest. Although JobCentre Plus, LSC and RDA s are named as lead partners in developing MAAs, with a 'duty to cooperate' there is nothing in the documentation to suggest that this is the case in LAAs.

- Conflict resolution between tiers. County councils are the main drivers of a county wide LAA as well as being the accountable body District councils are statutory bodies who are members of LAA working groups and LSPs, but their decisions may well be overturned at the higher tier level. The need to co-ordinate activities and dovetail into the LAA framework may prove to be problematic, particularly when different political parties are in power at each level. 
- Procurement and Commissioning. How will LSPs be measured on their capacity to procure and commission services on behalf of a locality? What criteria will be used? How will decisions be challenged? In some areas of the country LSP are the commissioning bodies, but in others Public Sector Boards are tasking on this role. Will Office of the Third Sector, Cabinet Office plans to train 2000 commissioners be sufficient and how will transfer of knowledge be facilitated from central commissioners to local areas?

- Risk Assessment and Scenario Planning. Which body will carry out a risk assessment of activities ands scenario planning? The LAA, the LSP or the lead Local Authority? Local Authorities are required under CAA to produce an Annual Risk Assessment, but no indication that LAA will have to do either a separate one, or a joint one with the LA.

- Timing issues. LAA $s$ will be 'signed off' by the Minister for CLG and refreshed annually but the timing of this process may be out of kilter with other targets at European, national, sub-regional and local levels. Targets for the multiplicity of agencies involved in LAAs may be mis-aligned and the timeframes for the Integrated Regional Strategy (which will be signed of jointly by the Ministers for CLG and DBERR) may differ.

- Engaging business, parish councils and community/third sector groups. In view of 'community calls for action' and a greater prominence given to communities of interest in LGWP, how are LAAs engaging these interests?

\section{Conclusion: Leading neighbourhoods, sub-regional sand local spatial levels}

The raft of policy documents emanating from central government on Modernising Local Governance have focused on the importance of giving communities a new voice and choice in governing their own affairs. The consultation paper (2005) proposed numerous changes to the structure and responsibilities of LSPs and related governance arrangements at the local level, not least the suggestion that LSPs may become commissioners of services on behalf of the locale, rather than advisory bodies as they currently exist. It is clear that some LSPs are already commissioning work (as an example many have used the services of consultancy companies to carry out village appraisals, strategy workshops, engaging stakeholders, and so forth). There are some LSPs that have established Local Service Boards, or Single Delivery Vehicles/Partnerships, and the example of Liver- pool Include is cited as evidence of good practice. This is a non profit regeneration company owned by Liverpool City Council and a registered social landlord, and it comes under the auspices of the LSP as LSP partners are charged with pulling together all assets and budgets. Local Service Boards will become an overarching framework to map and influence public spending in a particular area (ODPM, 2005) but there is no guidance on whether or not these PSB s will be at regional level (in which case they will be hierarchically above the sub-regional, local and neighbourhood levels of governance), at sub-regional, local or whether they will be the responsibility of the LSP. There has been little consideration given to the relationship between PSBs and LSPs, or indeed whether there are any accountability linkages between them. Where exactly do PSB s fit into the LSP framework if LSPs are given a statutory basis? This needs to be clarified.

However, it is clear that now that the work of Childrens' Trusts and PCT activities have been absorbed into LSPs, there remain difficulties in who has responsibility for issues such as personnel, resources, funding streams, and how will these be dovetailed from existing structures into a common framework. There is also an issue of whether the expertise or information is available to all LSP partners on decisions will be made prior to the commissioning external services and activities.

In addition there is a clear recognition that there may be many difficulties in developing a Sustainable Community Strategy. It is still unclear what the relationship between LSPs and Sustainable Community Strategies, or that between LSPs and the LAA framework. Some local authorities are working directly with the LSP to develop the targets, others are dovetailing LSP priorities into the LAA Framework, where still others are drawing in partners from existing regional and sub-regional partners, including LSP s to align their activities. This is causing some considerable conflict in many areas of the country, not least because it has taken some LSP s almost three years, and considerable consultancy support to get to the level where they have identified priorities.

Regional and local co-ordination is a perennial problem, mainly because each region and sub-region contains NRF (WNF) LSPs and non-NRF (WNF) LSPs. Moreover, not all regions and sub-regions have rationalised their partnerships, so there is still duplication of effort, despite the recent introduction of MAAs, and the need to combine Regional Economic Strategies (RES), Regional Spatial Strategies (RSS) into an Integrated Regional Strategy which dovetails with Sub-Regional Strategies. In some parts of the UK, where there 
are two tiers of local authority (county and district) concordats and joint working arrangements had been established, but in some areas this has not happened harmoniously. Cross boundary arrangements, particularly between neighbouring districts (on issues such as waste disposal) or neighbouring counties and unitaries (on police, fire or other criminal justice of community safety issues) there are long standing arrangements. Spatial Planning and the relationship between Local Development Frameworks had been variable across all local authority areas, and not all LSPs have a planner on the partnership, or have any way of feeding community objectives into the Local Development Framework. Although LDFs are statutorily required to engage with local communities in developing the Local Plan, and LSP $s$ are expected to engage with communities of interest (notably business and commercial, voluntary band community sectors) this remains a weakness.

At present most county and district councils have drawn together the relevant agencies to develop local priorities based on existing data to satisfy the requirements of LAAs, and this has presented some problems, in particular with regard to education and health.

Two important factors will determine the future working and operation of LSPs and LAAS. Firstly, the on going consultation on the future of LSP $s$ does confirm that these bodies will remain a central tenet in the Government's vision of devolving decision making to local communities. Secondly, the proposals to re-organise local government structures to achieve unitary authority status across England may split LSP territorial coverage, and divert attention away from prioritising the overall needs of any local area. In the NE of England, as an example, the Referendum on a Regional Assembly was accompanied by a potential re-organisation of local government into unitaries (if there had been a YES vote) and this process caused considerable conflict between existing counties and combinations of districts, as each sought to establish evidence to support their case for unitary status. It is likely that a proposal to establish unitary authorities will revive old rivalries throughout England, and this might have the effect of souring cordial working relationships between the levels of governance.

Regardless of any new structural arrangements of local government, councils are still going to be expected to take on a community leadership role. However, anecdotal evidence from some local authorities suggests that this leadership role may be more difficult to assert than central government assumes. In some local areas, the aims of the LSP may be at variance with the local authority aims. Moreover, the overview and scru- tiny committees of local authorities, as the responsible authority through which funds are channelled, are the accountable body, so it is possible that if LSP activities and priorities are contrary to the local authority, then it remains to be seen as to whose view will prevail.

In some areas of the country regional, sub-regional and local government work harmoniously, and draw all their strategies together into the LAA and MAA frameworks, but in others the old rivalries have surfaced, and little agreement is reached on what the priorities should be. In areas of England where NRF(WNF) funded LSPs border non-NRF (WNF) funded LSPs it has been difficult to get the partners to work across boundaries on joined up issues. Regional and local co-ordination takes time to establish, and in some areas of the country this is still at an early stage of development.

The Policy documents referred to in this paper, including the on-going Consultation on LSP $s$ are built on an assumption that all relationships between local authorities, LSP s, and their communities of interest, when in fact some are replete with conflict and disharmony. Moreover, there seems little in the documents to suggest that central government has given any clear commitment to placing a mirror up to its own inefficiencies, and instead suggested that if communities can wrest control from local authorities and other local agencies, and bring them to account for deficiencies then all will be well with the world. No suggestions are made on how the bureaucratic heritage continues to conflict with the new networked forms of govemance.

The conceptual 'wooliness' exemplified in current policy documents, where words like empowerment, subsidiarity, double devolution, power gap, are bandied around with little clarification, makes it even more difficult to establish whether indeed local people will have more 'choice' and a greater 'voice' in governing and managing their localities.

A Joseph Rowntree Foundation Report on the Implementation Gap suggests that 'communities are painfully aware that government rhetoric on empowerment does not really translate into anything substantial' (Downer, New Start, 19th May 2006:18) and the then Minister, Ruth Kelly was urged to provide answers to the following fundamental questions:

- How can top-down agendas be carried out?

- Who makes sure it happens?

-Who supports communities?

- Who do the communities go to when it is not working?

She, and her successor Hazel Blears, the current Minister, face an uphill task, because, as Geddes (2006: 76-97) suggests: 
'Local Strategic Partnerships can appear to open up new approaches to legitimacy, and the new possibilities of enhancing the capacity of the local governance system. In fact, however, they are more likely to undermine democracy and accountability, and lack the capacity to be effective, while limiting local policy options to those consistent to New Labour's neoliberal policy agenda'.

This paper has acknowledged the importance of collective leadership to drive reform and modernise public services and confirmed that leadership does matter in transforming local, sub-regional and regional areas. The UK Government has supported leadership and skills development in many central and local government agencies to facilitate the necessary changes (Milner - Joyce, 2005) because the complex nature of regional and local regeneration makes it imperative to bring together key stakeholder groups of members, policy makers, practitioners, other representative agencies, from diverse backgrounds, and as many communities of interest as possible to facilitate dialogue.

A 'bottom up' rather than a 'top down' approach to leading change is the declared model for UK Governance, but partnerships as the preferred institutional arrangement may simply be, as Davies (2004), suggests a stage of 'Punctuated Evolution', between embedding new forms of governance arrangements within a more traditional system of hierarchical government. If this is the case, then quite unstable ensembles of actors who continue to have clashes of values and differing interests are being asked to lead communities whilst state hierarchy persists and the rhetoric of autonomy continues. Countless constraints remain if a managerialist, rather than political discourse of messiness, conflicts, contestability, negotiation, and bargaining dominates.

For Coaffee and Headlam (2007) we might refer to these new arrangements as 'pragmatic localism' because getting partners together in collective leadership forums is a worthy aim to produce more effective and efficient decision making, but while central government offers pragmatic solutions with limits, and continues to have the right to intervene at will, the autonomy of localities remains questionable. Central Government is offering local communities and those who lead them a suite of changes from individualised service provision, to asset buy outs, community calls for action, greater scrutiny, involvement of private sector and civic representatives in new forums for decision making, but without a radical change to the representative forms of democratic accountability they will all serve to further problematise existing understandings of collective leadership in resolving local and regional problems.

\section{Foot-notes}

* The study was presented at a conference ( "Contesting Regional Pheripherality Through Leadership: Central European Experience") organized by Corvinus University of Budapest, in February, 2008.

1 This multi-spatial approach to regeneration and economic development also includes the establishment of National and Regional Efficiency and Improvement Partnerships, a new National 'Places Survey', a Sub Regional Review of Economic Development and Regeneration, new Integrated Regional Strategies, the creation of Leaderships Coalitions, Expert Panels, combined Inspectorates, and a new intervention Toolkit, among other changes.

${ }^{2} \mathrm{CPA}$ is now being replaced by CAA (Comprehensive Area Assessment) with a requirement for Local Authorities to work across organisational boundaries on LAAs (Local Area Agreements) and MAAs (Multi Area Agreements). They will be assessed on how well they have engaged with partners, how well they have involved communities of interest in addition to Risk Assessment, scored use of resources, scored direction of travel, performance data on national indicators.

${ }^{3}$ The 2006 LG White Paper had 200 indicators, and according to CLES, Centre for Local Economic Strategies, far from reducing the burden of 1200 targets to 198 targets, the NPF still includes over 600 targets, if other policy fields at the local level are considered (N MCIlnroy, CLES, Regeneration is 30, Liverpool, January 29-30" 2008 ) .

${ }^{4}$ Government Guidance states that an array of non-local authority partners should be involved in agreeing and developing LAAs with key roles for Town and Parish Councils.

5 The Quirk Review on Asset Buy Out, 2007

\section{References}

Agranoff, $R$. - McGuire, M. (1999): Big questions in public network management research. Paper presented to the Fifth National Public Management Research Conference, Texas A \& M University, College Station, Dec. 3-4 th

Audit Commission (2002): A Force for Change: Central Government Intervention in failing local authorities, London, Audit Commission

Audit Commission (2005): Comprehensive Performance Assessment, 2005, London, Audit Commission

Audit Commission (2007): The transition from CPA to CAA: Consultation, London, April 2007

Back, H. - Haus, M. - Heinhelt, H. - Stewart, M. (2003): Urban Governance and Democracy: Leadership and Community Involvement, Scandinavian Political Studies, 26 (2)

CLG (2007): A New Performance Framework for Local Authorities and LA Partnerships, October

$C L G$ (2007): Blears gives the green light to sub-regional jobs boost, www.communities.gov.uk, $7^{\text {th }}$ November 2007, retrieved $8^{\text {th }}$ November 2007

Coaffee, J. - Headlam, N. (2007): Pragmatic localism uncovered: The search for locally contingent solutions to national reform agendas, Geoforum (2007), doi:10.1016/j.Geoforum. 2007. 06. 010 
Communities and Local Government (2008): Community Cohesion Impact Assessment and Community Conflict Resolution Toolkit, CLG, London

County Durham Strategic Partmership LAA meeting, January 2006, Ramside Hall, Durham, UK

Davies, J.S. (2007): Conjuncture of Disjuncture? An institutional analysis of local regeneration partnerships in the UK. International Journal of Urban and Regional Research, 28 (3): 570-85

$D C L G$ (2006): Strong and prosperous communities, London, DCLG

DCLG (2006): Strong and prosperous communities: The Local Government White Paper, October 2006, Cmnd 6939

Department of the Environment, Transport and the Regions (1998): Modern local government: in touch with the people. London, HMSO, July

Department of the Environment, Transport and the Regions (2000): The Local Government Act 2000, Part 1, Promotion of Economic, Social and Environmental Well Being, 28 $8^{\text {th }}$ July 2000

Downer (2006): The Implementation Gap, New Start Magazine, London, $9^{\text {th }}$ May

Epstein and Fass Associates (2007): Kansas City, District of Columbia and Prince William, County Virginia Strategic Plans, New Jersey

European Institute of Urban Affairs, Liverpool, UK, OPM, University of Warwick, UK, University of West of England, Bristol, UK and ODPM, London, UK (January 2006): National Evaluation of Local Strategic Partnerships and Action Research Plan, 2002-5, Final Report, Office of the Deputy Prime Minister and Department of Transport

Geddes, M. (2006): Partnerships and the limits to local governance in England: Institutionalist Analysis and Neoliberalism, International Journal of Urban and Regional Research, 30 (1), March 2006: 76-97

HMTreasury, DBERR, CLG(July 2007): Review of sub-national economic development and regeneration. London

Improvement and Development Agency (2001): Benchmark of the 'ideal' local authority. Third edition, August. Available at: www.idea.gov.uk

Liddle, J. - Townsend, A.R. (2003): Reflections on the development of Local Strategic Partnerships: Key emerging issues, Local Governance, 29 (1): 37-54

Liddle, J. (2008): Local Area Agreements: Some early reflections. Regions' Newsletter, RSA, Seaford, Spring

Martin, S. - Bovaird, T. (March 2005): Meta-evaluation of the Local Government Modernisation Agenda: Progress Report on Services Improvement in Local Government, London, UK, OPDM

Martin, S.J. - Ashworth, R.E. - Boyne, G.A. - Dowson, L. - Enticott, T. - Entwistle, T. - Law, J. (2005): Evaluation of the Long Term impact of the Best Value Regime: Second Interim Report, ODPM. London
Miliband, D. (2006), Minister for Communities and Local Government, Empowerment and the Deal for Devolution, New Local Government Network, Manchester, UK, $18^{\text {th }}$ January 2006

Milner, E. - Joyce, P. (2005): Lessons for Leadership, Abingdon, Routledge

Office of the Deputy Prime Minister (December, 2005): Consultation Paper 'Local Strategic: Shaping their future: a Consultation paper', London, UK, ODPM

Office of the Deputy Prime Minister (ODPM) and Department for Transport (DfT) (2005): National Evaluation of Local Strategic Partnerships - Interim Report. London: ODPM

Office of the Deputy Prime Minister (ODPM) (2004): Skills for Sustainable Communities: The Egan Review. London: ODPM

Office of the Deputy Prime Minister (ODPM) (2004): The Future of Local Government: developing a 10 Year Vision. London: ODPM

Office of the Deputy Prime Minister (ODPM) (2005): Citizen Engagement and Public Service: Why neighbourhoods Matter. London: ODPM

Office of the Deputy Prime Minister (ODPM)(2005):Leadership in the Fire and Rescue Service. London: ODPM

Office of the Deputy Prime Minister(ODPM) (2005): Vibrant Local Leadership. London: DPM

Office of the Deputy Prime Minister (ODPM) (2006): Citizen Empowerment and the deal for Devolution. ODPM, London

Office of the Deputy Prime Minister (ODPM) (2006): Closing the Gap. London: ODPM

Quirk Report (2007): The Cabinet Office Report, Making Assets Work: The Quirk Review of Community Management and Ownership of Assets, London

Mcllnroy, N. (2008): Presentation to 'Regeneration is 30' Conference, Liverpool, 29-30 th January

Shared Intelligence (2007): Strategic cross-boundary working-how will MAAs help? Local Agreements Network, Seminar February 2007, London

Sotarauta, M. (2005): Shared leadership and dynamic capabilities in Regional Development, in Sagar and Halkier (eds) Regionalism Contested: Institutions, Society and Governance. Urban and Regional Planning and Development Series, Cornwall, Ashgate

The Sloan Foundation quoted on www.resultrsmatter.net/ site/model, retrieved $10^{\text {th }}$ Nov 2007

Van Ryzin, G.G. - Burgrud, E. - Di Padova, L. (2007): Leading from the ground up, Leading the future of the Public Services, ASPA-EGPA Transatlantic Dialogue on Public Leadership, University of Delaware, USA 31st May-2nd June, 2007)

www.oneworldaction.org/indepth/project.jsp?project.209, retrieved $10^{\text {th }}$ Nov 2007. 